\title{
Deveres do juiz diante do princípio da cooperação e sua relação com a
}

\section{fungibilidade/adequação}

\author{
Duties of the judge before the principle of cooperation and its relation to fungibility / adequacy \\ Deberes del juez ante el principio de cooperación y su relación con la fungibilidad / adecuación
}

Recebido: 05/03/2021 | Revisado: 11/03/2021 | Aceito: 15/03/2021 | Publicado: 21/03/2021

Letícia Bianca Pinheiro

ORCID: https://orcid.org/0000-0002-7227-9894

Universidade Paranaense, Brasil

E-mail: leticiabiancap@hotmail.com

Miriam Fecchio Chueiri

ORCID: https://orcid.org/0000-0003-4658-5414

Universidade Paranaense, Brasil

E-mail: mfecchio@prof.unipar.br

Kelly Cardoso

ORCID: https://orcid.org/0000-0002-0216-9809

Universidade Paranaense, Brasil

E-mail:servjuskelly@gmail.com

\begin{abstract}
Resumo
O presente trabalho tem como objetivo a visualização do princípio da cooperação e do seu alcance no âmbito processual, observado que, no Código de Processo Civil de 2015, surge como postulado importante à efetividade jurisdicional, norteando as relações dos sujeitos processuais. Trata-se de uma pesquisa bibliográfica de natureza qualitativa, trazendo o princípio da cooperação em uma visão diferente do que se costuma encontrar, pois enfatiza-se neste artigo o papel fundamental do Juiz no processo cooperativo, e não somente das partes (autor e réu), vez que, sem a cooperação dos magistrados, existe a possibilidade das decisões de mérito não observarem sua real finalidade. Diante disso, também apresentar-se-á a importância da fungibilidade/adequação nesse contexto, de forma a concluir que não há processo adequado, justo e célere, sem a cooperação das partes envolvidas no litígio e dos sujeitos processuais - partes, advogados, juízes, serventuários, peritos, intérpretes e também terceiros interessados.
\end{abstract}

Palavras-chave: Cooperação; Deveres; Partes; Juiz; Fungibilidade.

\begin{abstract}
The present work, with the objective of visualizing the principle of cooperation and its non-procedural scope, observed that the Code of Civil Procedure of 2015, emerges as an important postulate of judicial effectiveness, guiding the relations of two procedural subjects. It is a qualitative bibliographic research, tracing the principle of cooperation from a different perspective than the one usually found, this article emphasizes the fundamental role of the non-cooperative process, and not subject to the parties (plaintiff and defendant), since two magistrates cooperate, there is a possibility that decisions on the merits do not respect their real purpose. On the other hand, the importance of fungibility / adequacy of the context is also outlined, in order to conclude that there has not been an adequate, fair and just process, there is cooperation between the parties involved, non-litigation, and two procedural matters individual matters, including the parties, defendants, judges, servants, experts, interpreters and also interested third parties.
\end{abstract}

Keywords: Cooperation; Duties; Parties; Judge; Fungibility.

\section{Resumen}

El presente trabajo, con el objetivo de visualizar el principio de cooperación y su alcance no procesal, observó que el Código Procesal Civil de 2015, emerge como un importante postulado de efectividad judicial, orientando las relaciones de dos sujetos procesales. Se trata de una investigación bibliográfica cualitativa, trazando el principio de cooperación desde una perspectiva diferente a la que se encuentra habitualmente, este artículo enfatiza el papel fundamental del proceso no cooperativo, y no sujeto a las partes (demandante y demandada), ya que dos magistrados cooperan, existe la posibilidad de que las decisiones sobre el fondo no respeten su propósito real. Por otro lado, también se destaca la importancia de la fungibilidad / adecuación del contexto, a fin de concluir que no ha habido un proceso adecuado, justo y equitativo, hay cooperación entre las partes involucradas, no litigio, y dos cuestiones procesales - materias individuales, incluyendo las partes, imputados, jueces, servidores, peritos, intérpretes y también terceros interesados.

Palabras clave: Cooperación; Deberes; Partes; Juez; Fungibilidad. 


\section{Introdução}

O Princípio da cooperação é fruto do modelo cooperativo de processo (Cambi, Haas, Schitz, 2017, p. 345-346), modelo baseado na ideia de processo justo, e norteia-se na participação cooperativa do juiz para com as partes, essencial para que reflita de forma efetiva os pressupostos constitucionais (Marinoni, Arenhart, Mitidiero, 2016, p. 172).

O modelo da cooperação/colaboração, intenta a organização do papel das partes e também do juiz na construção do processo, formando um tipo de comunidade de trabalho conjunto e equilibrado.

O princípio da cooperação, portanto, tem como finalidade a participação solidária dos sujeitos processuais de modo a construir a decisão final durante o processo, de forma conjunta e equilibrada (Cambi, Haas, Schitz, 2017, p. 345-346).

Ademais, por sujeitos processuais, entendem-se todos aqueles que influenciam na resolução de uma ação (partes, advogados, juízes, serventuários, peritos, intérpretes e também os terceiros interessados) (Araújo, 2016, p. 181).

Trazido por alguns autores como princípio da colaboração (Marinoni, Arenhart, Mitidiero, 2016, p. 164), o princípio da cooperação não pressupõe o fim da litigiosidade e de todo o conflito que nos leva à busca jurisdicional, mas que os sujeitos processuais auxiliem o processo, objetivando a busca de uma solução considerada justa (Araújo, 2016, p. 177-178).

Quanto à terminologia adotada (cooperação e colaboração), a colaboração nos parece menos adequada, por supor que aquele que colabora está, por vezes, abrindo mão daquilo que deseja em prol do outro - em uma visão contenciosa. Já a cooperação, estaria vinculada à ações dos sujeitos que visem benefício para todas as partes, sem que alguma tenha que abrir mão do que deseja, mas mantendo a ideia de se alcançar uma decisão justa e efetiva.

O conflito é importante para o desenvolvimento e amadurecimento democrático das relações sociais, ou seja, por mais que seja considerado um rompimento da harmonia das relações, é vital (Spengler \& Spengler Netto, 2014, p. 14), e isso também não quer dizer que as convenções e acordos não são vitais.

Também não há mais lugar para o entendimento de que quem deve protagonizar o processo são as partes e ao juiz caberia somente observar o duelo, velando os procedimentos ao invés de tentar pacificar o conflito (Buzzi, 2017, p. 268).

A visão que se traz da ideia de que a cooperação é mais adequada que a colaboração, se dá na perspectiva de imparcialidade de todos os sujeitos processuais que, de alguma forma, levam ao deslinde do processo com o objetivo de trazer - não a busca da verdade real, mas daquela que melhor atenda aos interesses das partes, levando-se em conta as provas produzidas ao longo da ação.

É válido ressaltar que o princípio da cooperação não implica colaboração entre as partes, pois obviamente ambas têm interesses diferentes; portanto, a cooperação deve existir das partes para com o Estado-juiz e, por consequência, com o próprio processo (Marinoni, Arenhart, Mitidiero, 2016, p. 174).

Antes do CPC/2015, esse princípio estava de certa forma contido nos princípios da celeridade processual, da razoável duração do processo, do contraditório e da ampla defesa, do devido processo legal e da boa-fé.

O CPC/2015 trouxe, em seu artigo $6^{\circ}$, a disciplina expressa do princípio da cooperação, que antes, apesar de existir na doutrina, jurisprudência e por analogia aos demais princípios existentes, não tinha previsão legal.

Dispõe o artigo $6^{\circ}$ do CPC/2015 que "Todos os sujeitos do processo devem cooperar entre si para que se obtenha, em tempo razoável, decisão de mérito justa e efetiva".

Derivado de diversos princípios constitucionais, o princípio da cooperação decorre, principalmente, do devido processo legal, da boa-fé processual e do contraditório (Medeiros Neto \& Pinto, 2019, p. 05).

Destaca-se que, o princípio da cooperação é um dever e não um ônus (Figueiredo, 2017, p. 16), mas que implica em outros deveres. Tendo como objetivo a visualização do princípio da cooperação e do seu alcance, observado que no CPC/2015 surge como postulado importante à efetividade jurisdicional - norteando as relações dos sujeitos processuais - aprofundaremos este artigo nos deveres do juiz para com as partes, pois entendemos que apesar de não possuírem hierarquia, o juiz teria visão 
imparcial e privilegiada do todo processual, de forma a visualizar habilmente eventuais adequações necessárias ao bom deslinde das ações e, portanto, poderia cooperar de forma mais efetiva para uma decisão justa.

\section{Metodologia}

A escolha metodológica do presente estudo é a pesquisa dedutiva. Tendo em vista que há também a interpretação por parte do pesquisador, trazendo informações e conhecimentos, porém não com citações isoladas, mas com análise interpretativa e tendo em vista a alocação prática do estudo. De acordo com Marconi e Lakatos (2003, p. 92) o método dedutivo: “[...] tem o propósito de explicar o conteúdo das premissas [...]", sustentando de modo completo a conclusão.

O artigo objetiva trazer uma nova visão a respeito do princípio da cooperação que muitas vezes é tido somente como dever das partes, instigando a reflexão e indagação crítica acerca da relação dos sujeitos processuais no decorrer do litígio.

\section{Resultados e discussões}

\subsection{Cooperação do juiz com as partes}

Tendo em vista que a cooperação deve ocorrer das partes para com o Estado-juiz e com o processo efetivamente falando, mas também do juiz para com as partes (Marinoni, Arenhart, Mitidiero, 2016, p. 174), necessária a observância dos deveres processuais decorrentes desse princípio, quais sejam: o de esclarecimento, de consulta ou diálogo, de prevenção e de auxílio ou adequação (Cerqueira \& Pessoa, 2016, p. 299).

Esses deveres processuais são regras a serem seguidas pelo juiz na condução do processo. O dever de esclarecimento, consubstancia-se no dever que o juiz tem de ajudar a sanar dúvidas quanto à posição das partes para com os fatos e mesmo sobre os pedidos realizados. Já o dever de consulta ou diálogo consiste em conversar com as partes antes de decidir sobre questões controversas. Na sequência, o dever de prevenção, o qual incumbe ao juiz indicar escolhas equivocadas que as partes realizaram do ponto de vista processual e que podem prejudicar no exame do mérito; e, por último, o dever de auxílio ou adequação, o qual visa à retirar os obstáculos que dificultem ou impeçam o exercício dos direitos das partes, de forma a cumprir a finalidade do processo (Marinoni, Arenhart, Mitidiero, 2016, p. 174).

Alguns autores veem essas regras não só como deveres do juiz para com as partes, mas das partes para com o juiz. Assim, o dever de esclarecimento estaria ligado ao Juízo se fazer entender, fundamentando de forma pormenorizada suas decisões e tirando qualquer dúvida que fosse apresentada pelas partes. O dever de consulta ou diálogo, estaria vinculado ao caráter democrático das relações jurídicas, viabilizando o esclarecimento dos sujeitos do processo através das oitivas das partes (Cerqueira \& Pessoa, 2016, p. 302). O dever de prevenção seria uma forma do juiz auxiliar as partes a prevenir que eventuais equívocos interfiram na sua decisão; e por fim, o dever de auxílio ou adequação, visualiza-se no dever de os magistrados receberem aos advogados quando procurados para tanto, possibilidade trazida pela Lei $n^{\circ} 8.906 / 94$, artigo $7^{\circ}$, inciso VII, pois, vejamos, ao receber o procurador da parte, poderia, o juiz, auxiliar e adequar eventuais dúvidas ou pontos por meio de diálogo com o representante da parte.

Dessa forma, notamos que os deveres decorrentes do princípio da cooperação são uma via de mão dupla e, apesar de, na prática, parecer muitas vezes que essa cooperação deva ocorrer somente das partes para com o juiz e o processo, é de suma importância a cooperação do juiz para que seja possível a construção de uma solução justa, efetiva e em tempo razoável. Guilherme Assis de Figueiredo (2017, p. 18) destaca o papel do juiz:

O CPC em vários artigos expõe o poder de condução do processo pelo Juiz em seus artigos $105,110,113, \S 2^{\circ}, 182$, $\S 2^{\circ}, 262,267, \S 1^{\circ}$ e $\S 3^{\circ}, 284$, na fase de instrução, os artigos 130, 342, 343, 355, 399, 418, 440, 446, 451, e outros, portanto as partes devem exigir do juiz uma atuação efetiva com a participação das partes, devendo estas também 
colaborar, não mais se admitindo a figura do Juiz inerte e passivo, posto que uma participação mais ativa do magistrado não retira a garantia do contraditório, mas sim a reforça.

Nesse sentido, o CPC/2015 nos traz, por exemplo, o artigo 10, afirmando que:

[...] o juiz não pode decidir, em grau algum de jurisdição, com base em fundamento a respeito do qual não se tenha dado às partes a oportunidade de se manifestar, ainda que se trate de matéria sobre a qual deva decidir de ofício.

$\mathrm{Na}$ mesma seara, estão os artigos que vedam a decisão surpresa, os artigos que trazem a necessidade de fundamentação da decisão judicial e, ainda, os demais artigos que falam acerca da necessidade de o Juízo ouvir as partes antes de proferir sua decisão.

O CPC/2015 tratou com esses artigos, de trazer o princípio da cooperação ao processo civil, objetivando o melhor desenvolvimento do processo e, mais uma vez, trazendo de forma implícita aquilo que a Lei no 8.906/94 elenca no seu artigo $6^{\circ}$, vez que, ao cooperar com as partes, o juiz demonstra que suas ações são hábeis a contribuir para a solução do litígio e, por conseguinte, reitera que não há hierarquia entre advogados, magistrados e membros do MP, tendo em vista o bem maior que é a resolução dos conflitos.

Além dos deveres inerentes à cooperação, já elencados, é importante mencionar os demais deveres dos magistrados como bem prelecionam Cândido Rangel Dinamarco e Bruno Vasconcelos Carrilho Lopes (2017, p. 95):

No quadro dos deveres do juiz, o art. 139 do Código de Processo Civil inclui o de a assegurar às partes igualdade de tratamento (inc. I), o de velar pela duração razoável do processo (inc. 11l), o de prevenir ou reprimir qualquer ato contrário à dignidade da justiça (inc. I1I), o de determinar as medidas necessárias para assegurar o cumprimento de ordem judicial (inc. IV), o de promover a autocomposição entre as partes (inc. V) etc. Deve ainda julgar preferencialmente as causas postas sob sua responsabilidade de acordo com a ordem cronológica, a partir do momento em que estiverem em condições de julgamento (art. 12). Tem o juiz o poder de exigir pontualidade aos auxiliares da Justiça, mas também o dever de ser ele próprio pontual (art. 226), podendo qualquer das partes representar aos órgãos competentes "contra juiz ou relator que injustificadamente exceder os prazos previstos em lei, regulamento ou regimento interno" (art. 235).

Todos esses deveres nos levam a intencionar que a solução do conflito para cumprir o dever cooperativo de decisão justa, efetiva e de tempo razoável, se daria sem o uso de ativismos judiciais e, destaca-se aqui, com a observância cada vez maior da fungibilidade e adequação, a fim de efetivação do cumprimento dos deveres jurisdicionais.

\subsection{Fungibilidade/adequação}

Ao trazer de forma efetiva a observância do princípio da cooperação para o processo, deve haver maior aplicação por parte do juiz, da fungibilidade/adequação ao processo, porque, em tese, a ideia do processo é a resolução do conflito e não o cumprimento exacerbado do formalismo processual. Afinal, o formalismo utilizado de forma desmedida, erradica qualquer hipótese de resolução adequada de mérito.

Ademais, a fungibilidade/adequação, encaixa-se em um dos deveres do juiz cooperativo que é o do auxílio ou adequação, conforme já mencionado.

Não aplicar a razoabilidade de forma a viabilizar a solução de mérito sempre que possível, leva o jurisdicionado a perder esperanças e desvirtua a missão institucional do Judiciário, pois, dessa forma, estaria barrando o acesso à justiça, o qual é garantido pela Constituição Federal (Theodoro Júnior, 2017, p. 36).

Para Humberto Theodoro Junior, (2017, p. 41) o CPC/2015, ao trazer o princípio da cooperação, assim como outros instrumentos aplicáveis ao processo, acredita estar apto a: 
[...] cumprir a missão de um processo justo capaz de realizar a tutela efetiva dos direitos materiais ameaçados ou lesados, sem apego ao formalismo anacrônico e de acordo com os princípios constitucionais democráticos que regem e asseguram o pleno acesso de todos ao Poder Judiciário

Ocorre que, na prática, apesar das boas intenções do CPC/2015, temos a insistência da preponderância do formalismo processual em boa parte dos processos, e a ideia da cooperação do juiz para com as partes nessa senda, cai por terra. Como pondera Dimitri Dimoulis e Soraya Lunardi (2016, p. 04):

O formalismo é criticado como postura que ignora a substância dos conflitos jurídicos. Se alguém é inocente, não deixa de sê-lo porque no dia da audiência não compareceu a testemunha que comprovaria sua inocência. Também não parece correto alguém perder um processo porque o estagiário do escritório de advocacia não conseguiu protocolar um recurso dentro do prazo!

Na mesma obra, os autores mencionam ainda que as críticas ao formalismo não podem ser aceitas tendo em vista que essas normas são necessárias e desempenham uma função social, além de serem essenciais para não transformar o processo em uma "discussão infinita e caótica" (Dimoulis \& Lunardi, 2016, p. 04).

Mister se faz a observância dessa análise, porque, de fato, o formalismo existe por motivos justificáveis. O que não se espera é que seu uso ultrapasse a finalidade maior do Judiciário - a solução de conflitos - para se tornar apenas um procedimento burocrático, demasiadamente formal, e que releva o fato dos processos não se resumirem à papeis e sequências de protocolos, mas sim às vidas dos jurisdicionados. Como leciona sabiamente Ronald Dworkin (1999, p. 3-4):

Os processos judiciais são importantes em outro aspecto que não pode ser avaliado em termos de dinheiro, nem mesmo de liberdade. Há, inevitavelmente, uma dimensão moral associada um processo judicia! legal e, portanto, um risco permanente de uma forma inequívoca de injustiça pública. Um juiz deve decidir não simplesmente quem vai ter o quê, mas quem agiu bem, quem cumpriu com suas responsabilidades de cidadão, e quem, de propósito, por cobiça ou insensibilidade, ignorou suas próprias responsabilidades para com os outros, ou exagerou responsabilidades dos outros para consigo mesmo. Se esse julgamento for injusto, então a comunidade terá infligido um dano moral a um de seus membros por tê-lo estigmatizado, em certo grau ou medida, como fora-da-lei. O dano é mais grave quando se condena um inocente por um crime, mas já é bastante considerável quando um queixoso com uma alegação bem fundamentada não é ouvido pelo tribunal, ou quando um réu dele sai com um estigma imerecido.

Ademais, corroborando com o mencionado, podemos extrair o mesmo sentido do artigo 277 do CPC/2015: "Quando a lei prescrever determinada forma, o juiz considerará válido o ato se, realizado de outro modo, lhe alcançar a finalidade". Exemplo disso, está na lição de Guilherme Assis de Figueiredo (2015, p.18):

O mesmo dever de cooperação é exigível dos nossos Tribunais, interposto o recurso com algum erro de recolhimento de custas ou de ordem formal, cabe primeiramente a intimação da parte a que regularize a peça processual, demonstrando uma visão mais voltada a solução efetiva do conflito do que ao preciosismo das formas processuais como até pouco tempo vigia em nossos Tribunais.

E aqui nos resta claro que o princípio da cooperação, liga-se intimamente com a fungibilidade/adequação, pois, assim, o juiz estaria cumprindo com os deveres de esclarecimento, de consulta ou diálogo, de prevenção, e de auxílio ou adequação, por consequência da aplicação do princípio. 


\section{Considerações Finais}

No viés prático, podemos observar o princípio da cooperação na aplicação de diversos artigos do CPC/2015, também em outros Códigos e na própria aplicação da Constituição, pois como já mencionamos, o princípio da cooperação decorre principalmente do devido processo legal, da boa-fé processual e do contraditório (Medeiros Neto \& Pinto, 2019, p. 05), os quais são princípios Constitucionais.

Quanto ao dever de esclarecimento, temos, de forma explícita, sua disciplina no $\S 1^{\circ}$ do artigo 357 do CPC: "Realizado o saneamento, as partes têm o direito de pedir esclarecimentos ou solicitar ajustes, no prazo comum de 5 (cinco) dias, findo o qual a decisão se torna estável." e reitera-se no seu $\S 3^{\circ}$.

Também nos artigos 387, 481, parágrafo único do artigo 483 e $\$ 2^{\circ}$ do artigo 735 do CPC, vê-se, de forma explícita, o dever de esclarecimento.

O dever de consulta ou diálogo, visualiza-se também dentro do dever de esclarecimento, mas tem como objetivo que juiz e partes conversem e decidam, de forma conjunta, sobre questões controversas, o que geralmente ocorre durante audiências específicas para solução dessas controvérsias ou nas demais audiências, mas que também pode ocorrer quando o juiz é consultado pelo advogado da forma que disciplina a Lei $n^{\circ} 8.906 / 94$, artigo $7^{\circ}$, inciso VII.

A consulta ou diálogo também se referem de forma enfática ao contraditório, e à necessidade de oitiva das partes e testemunhas, assim como da necessidade de as partes defenderem-se ao longo do processo, o que é trazido no CPC/2015 pelos $\operatorname{artigos} 7^{\circ}, 9^{\circ}, 10,11$ e $489, \S \S 1^{\circ}$ e $2^{\circ}$ (Marinoni, Arenhart, Mitidiero, 2016, p. 175).

O dever de prevenção pode ser visualizado nos artigos 317 e 932, parágrafo único do CPC/2015, sendo, como o nome já diz, uma forma de prevenir que algum vício possa prejudicar a decisão de mérito, dando-se assim a oportunidade para que a parte se manifeste e possa regularizar o problema antes de ser proferida decisão que possa lhe ser totalmente desfavorável (Marinoni, Arenhart, Mitidiero, 2016, p. 175).

Por fim, o dever de auxílio determina que o juiz "colabore com as partes no desempenho de seus ônus e no cumprimento de seus deveres no processo", conforme contido no artigo 722, III do CPC/2015 (Marinoni, Arenhart, Mitidiero, 2016, p. 175).

Conclui-se que o princípio da cooperação vai muito além de um mero princípio a ser observado na aplicação da Lei, mas deve ser colocado em prática no cotidiano judicial para evitar que decisões de mérito não observem sua real finalidade e de forma a evitar que o formalismo exacerbado prejudique as partes que, apesar de terem interesses opostos, buscam o mesmo fim: uma solução adequada e em tempo razoável.

\section{Referências}

Araújo, F. C. de. (2016). Curso de Processo Civil: parte geral: Malheiros.

Beraldo, M. C. S. (2011, agosto). O dever de Cooperação no Processo Civil. Revista de Processo. 198, 455-462.

Cambi, E., Haas, A., \& Schmitz, N. (2017, outubro). Princípio da Cooperação Processual e o Novo CPC - Revista dos Tribunais. 984/2017, $345-384$.

Buzzi, M. A. G. (2017, maio). O Princípio da Cooperação e a Audiência Prevista no artigo 334 do Novo Código de Processo Civil. Revista FONAMEC - Rio de Janeiro. https://www.emerj.tjrj.jus.br/revistas/fonamec/volumes/volumeI/revistafonamec_numero1volume1_263.pdf. 1(1), 263-272

Cerqueira, D. M., \& Pessoa, F. M. G. (2016, janeiro-junho). Direitos fundamentais processuais e o princípio da cooperação no novo Código de Processo Civil. Direitos Fundamentais \& Justiça,. <http://www.bidforum.com.br/PDI0006.aspx?pdiCntd=246178>. 10(340.

Dimoulis, D., \& Lunardi, S. (2016). Curso de Processo Constitucional - Controle de constitucionalidade e remédios constitucionais. (4a ed.), Atlas.

Dinamarco, C. R., \& Lopes, B. V. C. (2017). Teoria Geral do Novo Processo Civil. (2a ed.), Malheiros.

Dworkin, R. (1999) O império do direito. Martins Fontes. 
Research, Society and Development, v. 10, n. 3, e45210313574, 2021

(CC BY 4.0) | ISSN 2525-3409 | DOI: http://dx.doi.org/10.33448/rsd-v10i3.13574

Feliciano, G. G. (2016). Processo Social, Princípio da Cooperação Processual e Poderes Assistenciais do Juiz: aplicações ao processo civil e ao processo do trabalho - Revista do Tribunal Regional do Trabalho da 15a Região. https://juslaboris.tst.jus.br/bitstream/handle/20.500. 12178/108710/2016_feliciano_guilherme_processo_social.pdf?sequence=1\&isAllowed=y. n. 48.

Figueiredo, G. A.de. (2017). O Princípio da Cooperação no Novo Código de Processo Civil de 2015 - Processo, jurisdição e efetividade da justiça III. CONPEDI. http://conpedi.danilolr.info/publicacoes/roj0xn13/1743z27d/1 Kbp7ow2ky09Sg6H.pdf.

Lei $n^{\circ}$ 13.105, de 16 de março de 2015 -http://www.planalto.gov.br/ccivil_03/_ato2015-2018/2015/lei/113105.htm.

Lei $n^{o}$ 8.906, de 4 de julho de 1994. http://www.planalto.gov.br/ccivil_03/leis/18906.htm.

Marconi, M. de A., \& Lakatos, E. M. (2003). Fundamentos de Metodologia Científica. (5a ed.). Atlas.

Marinoni, L. G., Arenhart, S. C., \& Mitidiero, D. (2016). O Novo Processo Civil. (2ª ed.). Editora Revista dos Tribunais.

Medeiros Neto, E. M., \& Pinto, C. P. (2019, outubro). Notas sobre o Princípio da Cooperação - Revista de Processo. 296/2019, 63-88.

Spengler, F. M., \& Spengler Netto, T. (2014). A Boa-fé e a Cooperação Previstas no PL 8.046/2010 (NOVO CPC) como Princípios Viabilizadores de um Tratamento Adequado de Conflitos Judiciais. Revista de Processo. 230/2014, 13-32.

Theodoro Júnior, H. (2017). Curso de Direito Processual Civil. Teoria geral do direito processual civil, processo de conhecimento e procedimento comum. I. Forense. 